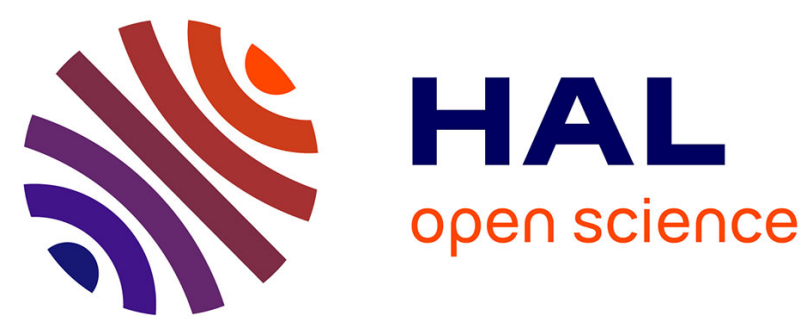

\title{
Adaptation and Validation of the Standardized Assessment of Personality - Abbreviated Scale as a Self-Administered Screening Test (SA-SAPAS)
}

Gaëtan Merlhiot, Laurie Mondillon, Nicolas Vermeulen, Anamitra Basu, Martial Mermillod

\section{To cite this version:}

Gaëtan Merlhiot, Laurie Mondillon, Nicolas Vermeulen, Anamitra Basu, Martial Mermillod. Adaptation and Validation of the Standardized Assessment of Personality - Abbreviated Scale as a SelfAdministered Screening Test (SA-SAPAS). Journal of Psychology and Psychotherapy , 2014, 4, pp.6 - 6. 10.4172/2161-0487.1000164. hal-01419303

\section{HAL Id: hal-01419303 https://hal.science/hal-01419303}

Submitted on 19 Dec 2016

HAL is a multi-disciplinary open access archive for the deposit and dissemination of scientific research documents, whether they are published or not. The documents may come from teaching and research institutions in France or abroad, or from public or private research centers.
L'archive ouverte pluridisciplinaire HAL, est destinée au dépôt et à la diffusion de documents scientifiques de niveau recherche, publiés ou non, émanant des établissements d'enseignement et de recherche français ou étrangers, des laboratoires publics ou privés. 


\title{
Psychology \& Psychotherapy
}

\section{Adaptation and Validation of the Standardized Assessment of Personality - Abbreviated Scale as a Self-Administered Screening Test (SA-SAPAS)}

Gaëtan Merlhiot ${ }^{1 *}$, Laurie Mondillon', Nicolas Vermeulen ${ }^{2}$, Anamitra Basu ${ }^{3}$ and Martial Mermillod ${ }^{4,5}$

${ }^{1}$ Clermont Université, Université Blaise Pascal, and CNRS, LAPSCO-UMR 6024, F-63037, Clermont-Ferrand, France

${ }^{2}$ Psychology Department, Université catholique de Louvain (UCL), Belgium

${ }^{3}$ Department of Humanities, Social Sciences \& Management, IIT Bhubaneswar, India

${ }^{4}$ Université Grenoble Alpes, LPNC, F-38000 Grenoble, France \&CNRS, LPNC, F-38000 Grenoble, France

${ }^{5}$ Institut Universitaire de France

\begin{abstract}
Personality disorder assessments are time-intensive and require trained interviewers. They are unlikely to be performed on a routine basis. In clinical and general populations, there is a requirement for short and robust self-administered screening tests for personality disorders. We first translated the original form of the SAPAS into French and validated it in a clinical sample ( $n=28)$. This adaptation revealed properties similar to those of the original version. The first and second studies validated the adaptation of the SA-SAPAS as a self-administered questionnaire in clinical $(n=45)$ and general $(n=186)$ populations. We were able to use the same cut-off (score $\geq 2$ ) in both the clinical and general populations and this permitted correct identification in $89 \%$ of the clinical subjects (sensitivity of $97.3 \%$; specificity of $50 \%$ ) and $86 \%$ in the general population (sensitivity of $87.5 \%$; specificity of $85.7 \%$ ). These results suggest possible applications for researchers and clinicians, either as a routine screening test or as a selection tool in both general and clinical populations.
\end{abstract}

Keywords: Personality disorders; Personality assessment; Screening tests; Clinical psychology; Psychiatry

\section{Introduction}

The prevalence of people with Personality Disorders (PDs) is fairly high even in the general population where it ranges from 3 to $15 \%[1,2]$. In psychiatric populations, its prevalence is about $30 \%$ among outpatients [3], 40\% among inpatients [4] and up to $70 \%$ in prison psychiatric populations [5]. Patients suffering from depression, substance abuse and/or eating disorders account for the highest proportion of PDs. In the fields of both primary health care and psychiatric care, patients with comorbid PDs experience poorer treatment outcomes (for recent epidemiologic studies, see [6,7]). Several studies have suggested that patients with cormorbid PDs require specific treatment (For depression: [8,9]; For eating disorders: [10]; For substance dependency: [11]).

The identification of PDs has therefore been the subject of considerable research and a wide range of screening tests, inventories and standardized interviews are now available. Various standardized interviews exist for the diagnosis of PDs: The Structured Clinical Interview for DSM-IV Personality Disorders (SCID-II) [12], The Structured Interview for DSM Personality-IV (SIDP-IV) [13], and the International Personality Disorder Examination (IPDE) [14]. Although a number of interviews or self-rated questionnaires are also used for PD screening, the number of interviews specifically designed for PD screening is limited: the Personality Assessment Schedule Rapid version (PAS-R) (30 items, 10 minutes to complete) [15] and the Standardized Assessment of Personality - Abbreviated Scale (SAPAS) (8 items, 5 minutes to complete) [16]. Most screening measures are based on the use of self-rated questionnaires, e.g., the Personality Diagnostic Questionnaire (PDQ 4+) (99 items, 20 minutes to complete) [17-20], the DSM-IV and ICQ-10 Personality Questionnaire (DIP-Q) (140 items, 20 minutes to complete) [21,22], the SCID-II Screen (115 items, 20 minutes to complete) [12], the IPDEQ (screen) from the IPDE (DSM-IV version 77 items, ICD-10 version : 59 items, 20 minutes to complete) [14]; the Personality Assessment Screener (PAS) (22 items, 5 minutes to complete) [23,24]; The Personality Disorder Screening (PDS) (12 items, 5 minutes to complete) [25]; the Iowa Personality Disorder Screen (IPDS) (11 items, 5 minutes to complete)
[26-28]; the Personality Disorder Screening - Short Version (PSS-K) (8 items, 5 minutes to complete) [29]; and the Standardized Assessment of Personality - Abbreviated Scale Self-Report (SAPAS-SR) (8 items, 5 minutes to complete) [30].

With reference more specifically to the use of trait personality questionnaires for PD identification, a recent study [31] compared the screening capacity for PDs of a categorical screen test, the SAPASSR [30], with that of a trait personality screen test, namely the NEOFFI (short version of the NEO-PI-R). The authors showed that the NEO-FFI, which is based on the Five Factor Model, one of the most widely used models of trait personality to study normal personality, had a poor screening capacity for PDs. Originally created by Costa and McCrae (1985), its latest version is known as the NEO-PI-3 [32]. Many articles have discussed the assessment of PDs using the Big Five model [33-36]. Obviously, this model does not seem to be the best choice for PD screening even though it is undoubtedly useful for gaining a better understanding of patients and their afflictions. It is widely acknowledged that research into personality would benefit from a better classification of PDs [6].

In choosing between the PD screenings, we focused on critical criteria such as the need of a short test in addition to the interview in both clinical and research settings, and the need of a tool with good screening capacities. It is important to note that neither the PDS nor the PSS-K had been published when we chose the best candidate for our

*Corresponding author: Gaëtan Merlhiot, Department of Psychology, Clermont Université, Université Blaise Pascal, 34 avenue Carnot 63037 Clermont Ferrand Cedex1, France, Tel: +33473406252; E-mail: gaetan.merlhiot@univ-bpclermont.fr

Received October 10, 2014; Accepted November 24, 2014; Published December 01, 2014

Citation: Merlhiot G, Mondillon L, Vermeulen N, Basu A, Mermillod M (2014) Adaptation and Validation of the Standardized Assessment of Personality Abbreviated Scale as a Self-Administered Screening Test (SA-SAPAS). J Psychol Psychother 4: 164. doi: 10.4172/2161-0487.1000164

Copyright: (c) 2014 Merlhiot G, et al. This is an open-access article distributed under the terms of the Creative Commons Attribution License, which permits unrestricted use, distribution, and reproduction in any medium, provided the original author and source are credited. 
study. We therefore concentrated on the SAPAS [16], which exhibited encouraging results regarding the time required for completion (i.e., less than 5 minutes), and regarding its screening capacities where DSM-IV PDs were correctly identified in $90 \%$ of participants with a sensitivity of $94 \%$ and a specificity of $85 \%$. Since the publication of the SAPAS in 2003, several researchers have used it in its initial form as an interview [37-47]. Various validations using new samples are also available [48-50]. Most of these have revealed a good classification of PDs as well as sensitivity and specificity levels similar to those originally found by Moran and colleagues [16]. Nevertheless, it is important to mention that the specific validation among depressive patient [50] yielded poorer results $(73.1 \%$ correct identification; sensitivity of $80 \%$; specificity of $70 \% ; \mathrm{n}=394)$. In addition, a study conducted in a substance abuser population [51] showed that the SAPAS correlated well with clinicians' ratings for "externalizing behavior" and "global assessment of functioning". Finally, the SAPAS exhibits robust PD associations for Cluster A and C but only an acceptable association for Cluster B [52]. In 2008, a Dutch translation, validation and adaptation of the SAPAS as a self-report (SAPAS-SR: [30]) yielded lower values than the initial SAPAS (cut-off score of 4; $81 \%$ correct identification; sensitivity of $82.5 \%$; specificity of $79.6 \%$ ). Since then, other studies have used the SAPAS-SR [53-56], and two of these have reported limited screening properties $[54,55]$. To our knowledge, given the performance achieved using only 8 items and the short time required for completion, the abbreviated form of the SAPAS is one of the most interesting of the short PD screening tests and deserves to be adapted as a self-report measure of PDs.

\section{The Current Study}

Our aim was to convert this screen test into a self-administered questionnaire while retaining a screening capacity for PDs as close as possible to that of Moran's initial version [16]. The properties of the previous adaptation of the SAPAS as a self-report questionnaire (SAPAS-SR) [30,55] were not as good as those of the initial version. One possible explanation for this might be the absence of an interviewer and/or the fact that the questions, which were designed to be asked by the interviewer, did not contain sufficiently explicit instructions. To prevent such problems, we introduced the use of confirmatory questions which made it possible to remain as close as possible to what an interviewer might do in an interview. It is primarily this addition that differentiates the present adaption of the SAPAS as a selfadministered questionnaire (SA-SAPAS) from the previous self-report SAPAS version (SAPAS-SR) [30]. We focused our study in this way in order to obtain a robust and versatile screening test for PDs that would be suitable for use in both general and clinical populations. Such a test would clearly have many uses in both routine examinations as well as in investigative tools. In addition, neither the IPDS nor the SAPAS has previously been translated and validated in a self-administered form in French.

The first aim of this study was to validate the properties of a French translation of the SAPAS in its original form (interviewer-administered) in a clinical sample (pre-test) and to adapt it as a self-administered test for use in both clinical (study 1) and general populations (study 2). The second aim was to examine the possible uses of the SA-SAPAS as a routine clinical screening test at the time of hospital admission and as an investigative tool in both clinical and general populations.

\section{Pre-test}

We initially tested the SAPAS in its interviewer-administered form in a population of psychiatric patients $(27$ women, 1 man, Mage $=$
28.2 years, $\mathrm{SD}=9.3$ ) recruited at the Centre Hospitalier Sainte-Anne (CMME), Paris, France. The SAPAS was first translated into French by a French native speaker. In line with the aims of the current study, a confirmatory question, similar to the instruction used in the original SAPAS, was added to each item to determine if "the description applies most of the time and in most situations".

This first step in our adaptation of the SAPAS highlighted its interesting diagnostic properties. We found that a cut-off of 3 resulted in a correct identification rate of $85.7 \%$, a sensitivity of $87.5 \%$, and a specificity of $83.33 \%$. These results are close to those obtained in Moran's study [16], which showed $90 \%$ correct identification, a sensitivity of $94 \%$, and a specificity of $85 \%$.

\section{Study 1}

The outcomes of the first stage (pre-test) led us to adapt the SAPAS in a way that increased its flexibility as a screening test. In study 1 , we first modified it so that it took the form of a self-administered questionnaire. We then validated it in a psychiatric sample in order to permit meaningful comparisons with the first stage of our adaptation and the original SAPAS.

\section{Method}

Participants: Psychiatric patients ( 32 women, 7 men, Mage $=35.2$ years, $S D=12.7$ ) were recruited at the Centre Hospitalier Sainte-Anne (CMME), Paris, France. The exclusion criteria were the presence of any disorder preventing a PD diagnosis (i.e. any excessive depression or delusional state, any serious physical condition, any understandingrelated disorder, any impairment to intellectual efficiency, or any language comprehension problem). The nature and potential risks of the study were fully explained and a written informed consent was obtained from each participant. The sample consisted of 39 new patients who were interviewed using the SCID-II. The clinical examination revealed the following Axis-I diagnosis: affective disorder $(n=19)$, anxiety disorder $(n=1)$, both affective and anxiety disorder $(\mathrm{n}=9)$, affective disorder and substance addiction $(\mathrm{n}=5)$, eating disorder $(n=2)$, eating disorder and affective disorder $(n=3)$.

\section{Measures}

The SAPAS and its translation: The SAPAS introduced by Moran et al. [16] was itself derived from the opening section of the informant-based Standardized Assessment of Personality (SAP) [57], which includes 8 probe items and provides a total score for the screening of PDs ranging from 0 to 8 (see appendix). It was originally written in English and the following procedure was used to translate it into French. First, the 8 items were translated into French by two French native speakers. These initial translations matched, each other for 6 out of the 8 questions. Only questions 4 and 6 did not match exactly, but the translations had nearly the same meaning. Specifically, the differences came from the translation of the word "worrier" and the expression "lose your temper". A suitable final translation was compiled from the two translations. Three back-translations were then produced by bilingual English and French native speakers. Only one of the 8 questions differed from the original form in English. For question 6 , one of the three back-translations was different from the question used in the original formulation, with "anxious" being used instead of "worrier". This outcome confirmed the accuracy of the performed translations and no further modification was introduced.

SCID-II: The Structured Clinical Interview for DSM-IV Axis II PDs (SCID-II) [12] is a semi-structured interview for the evaluation of PDs taken from the DSM-IV. It was initially constructed using the 
criteria for the various PDs covered by the DSM-III-R but has since been adapted to accommodate recent modifications. We used the French version of this interview [58].

Psychiatric diagnosis: In order to verify the reliability of the SCIDII interviews, the diagnoses obtained by the SCID-II interviews were compared to the already established diagnoses of PD. Psychiatrists performed those diagnoses based over several patients' interviews and monitoring during their hospitalization. Among the 39 patients interviewed with the SCID-II, 37 of them had an established diagnosis. On the basis of the 37 diagnoses, we obtained $94.5 \%$ of agreement (35 over 37 diagnoses were identical). We therefore computed a Kappa coefficient and we obtained a kappa value of 0.85 . Thus, we could conclude that diagnoses obtained by the SCID-II interviews were satisfactory.

SA-SAPAS: In this study, the test was adapted for use as a selfadministered, questionnaire-based screening test (see Appendix). The test included a paragraph containing written instructions because the participants might not pay attention to the experimenter's spoken instructions. Each item was presented with a confirmatory question. This reduced the risk of inappropriate answers and was similar to an interviewer asking if "it applies most of the time and in most situations". For example, if the answer to question one - "in general, do you have difficulty making and keeping friends? $(\mathrm{Y} / \mathrm{N})$ - was yes, then the confirmatory question asked whether this answer applied "most of the time and in most situations" (and the participant could answer $\mathrm{Y} / \mathrm{N}$ ). As far as scoring is concerned, only answers for which a positive response was given to the confirmatory question were taken into account.

Procedure: The procedure consisted of three steps. In the first step, the patients completed the SA-SAPAS. In the second step, conducted shortly afterwards, they responded to the SCID-II. The third step, during which the patients completed another SA-SAPAS, took place about 3 weeks later.

Statistical method: An AUC analysis was performed to determine sensitivity, specificity, cut-offs and correct classification percentages. The internal validity was determined using Spearman's intercorrelation and Cronbach's $a$. The test-retest was examined on the basis of a Kappa coefficient and Lin's concordance [59,60].

Results: As far as the prevalence and distribution of people with PDs are concerned, the patients exhibited a prevalence of PDs of $74.4 \%$ with the following distribution: $35.9 \%$ borderline, $17.9 \%$ avoidant, $12.8 \%$ dependent, $12.8 \%$ obsessive, $5.1 \%$ narcissistic, $5.1 \%$ passive aggressive, $5.1 \%$ depressive, $5.1 \%$ schizoid, $2.6 \%$ paranoid, $2.6 \%$ antisocial, $2.6 \%$ histrionic, $2.6 \%$ not specified. The mean number of PDs was $1.10 ; 48.7 \%$ of the sample had one PD, $15.3 \%$ two PDs, and $10.2 \%$ three PDs.

Internal consistency was analyzed with Spearman's intercorrelations for the items scored with the confirmatory questions. Most of the correlations were below 0.2 and not significant $(p \geq 0.05)$, thus indicating that the items investigate different personality traits. There was an inter-correlation between questions 4 (anger/losing temper) and 5 (impulsivity) $(r(37)=0.54, p \leq 0.0001)$, and between questions 4 (anger/losing temper) and 7 (dependency) $(r(37)=0.64, p \leq 0.0001$ ). Another significant - but negative - correlation was observed between question 1 (relational difficulties) and question 3 (distrust of others) $(r(37)=-0.4, p \leq 0.01)$. Table 1 shows the correlations between the different items and their corresponding confirmatory questions. The mean correlations were around 0.68 .
The second test was Cronbach's a which enabled us to determine whether the test refers to a single dimension (Table 2). Taking into account the fact that the 8 items refer to different personality traits, we observed moderate correlations ranging from 0.5 to 0.6. As expected, Cronbach's $\alpha$ based on items without the confirmatory questions was low $(\alpha=0.12)$. However, the level of reliability increased with the confirmatory question $(\alpha=0.40)$. The different items were consistent overall, with questions (1,2 and 3) exhibiting the lowest level of consistency and questions (4,5,6,7 and 8) the highest level. Although the test-retest sample was small $(\mathrm{n}=9)$, we obtained some results regarding stability over time, presented in Table 3 . The Kappa coefficients were over 0.75 , thus indicating that stability was acceptable. The two Kappa values of 1 were due to the small size of the sample. Lin's concordance was tested for the two different scoring methods, that is to say with (0.89) and without (0.93) confirmatory questions.

The AUC results are shown in Table 4. The analysis revealed an AUC of 0.895 (95\%, CI 0.78-1.0). The three possible cut-offs revealed interesting properties. A cut-off of 3 or more made it possible to achieve a balance with a correct identification of $80 \%$, a sensitivity of $80.6 \%$ and a specificity of $75 \%$. The other two cut-offs had very different properties. A cut-off of 2 increased sensitivity to $100 \%$, while reducing specificity

\begin{tabular}{|l|c|c|c|c|c|c|c|c|}
\hline QUESTION & 1 & 2 & 3 & 4 & 5 & 6 & 7 & 8 \\
\hline & 1 & 0.59 & 0.80 & 0.68 & 0.62 & 0.44 & 0.65 & 0.61 \\
\hline
\end{tabular}

Table 1: Inter-correlations between questions and their confirmatory questions of the SA-SAPAS in study 1.

\begin{tabular}{|c|c|}
\hline QUESTION & CLINICAL SAMPLE $(\mathrm{n}=39)$ \\
\hline $\begin{array}{c}\text { Total score } \\
\text { (Scored without confirmatory question) }\end{array}$ & 0.12 \\
\hline Total Score & 0.40 \\
\hline (Scored with confirmatory question) & Alpha coefficient if item removed \\
\hline Question 1 & 0.51 \\
\hline Question 2 & 0.42 \\
\hline Question 3 & 0.42 \\
\hline Question 4 & 0.26 \\
\hline Question 5 & 0.33 \\
\hline Question 6 & 0.34 \\
\hline Question 7 & 0.16 \\
\hline Question 8 & 0.43 \\
\hline
\end{tabular}

Table 2: Internal consistency of the SA-SAPAS with Cronbach alpha coefficient in study 1.

\begin{tabular}{|c|c|c|c|c|c|c|c|c|}
\hline QUESTION & 1 & 2 & 3 & 4 & 5 & 6 & 7 & 8 \\
\hline & 0.77 & 0.78 & 0.77 & 0.73 & 0.73 & 1 & 1 & 0.78 \\
\hline
\end{tabular}

Table 3: Kappa coefficient for each item using confirmatory question scoring method in study 1 .

\begin{tabular}{|c|c|c|c|c|c|c|c|c|c|}
\hline $\begin{array}{c}\text { CLINICAL } \\
\text { SAMPLE } \\
\mathrm{N}=39\end{array}$ & $\begin{array}{c}\text { Cut-off } \\
\text { score }\end{array}$ & Sensitivity & Specificity & + +LR & -LR & $+\mathrm{PV}$ & -PV & $\begin{array}{c}\text { Correctly } \\
\text { classified (\%) }\end{array}$ \\
\hline $\begin{array}{c}\text { cla } \\
\text { Scored with }\end{array}$ & $\geq 2$ & 100.0 & 50 & 2.00 & 0.00 & 88.5 & 100 & 90 \\
\hline $\begin{array}{c}\text { confirmatory } \\
\text { questions }\end{array}$ & $\geq 3$ & 80.6 & 75 & 3.24 & 0.26 & 92.9 & 50 & 80 \\
\hline & $\geq 4$ & 54.8 & 100 & 0.00 & 0.45 & 100 & 50 & 100 \\
\hline
\end{tabular}

$+\mathrm{LR}=$ Positive likelihood ratio; $-\mathrm{LR}=$ Negative likelihood ratio

$+\mathrm{PV}=$ Positive Predictive Value; $-\mathrm{PV}=$ Negative Predictive Value

$\mathrm{AUC}=$ Area under curve; $\mathrm{Cl}=$ Confidence interval

Table 4: Cut-off scores, sensitivity, specificity, and classifying power of the SASAPAS in study 1. 
to $50 \%$ and increasing correct identification to $90 \%$. Conversely, a cutoff of 4 or more increased specificity to $100 \%$ but reduced sensitivity to $54.8 \%$ and correct classification to $64 \%$.

\section{Study 2}

Since the prevalence of people with PDs is lower in the general population, it was necessary to verify the cut-off score and the properties of the test in this population. Study 2 was thus designed to validate the SA-SAPAS as a self-administered questionnaire in the general population.

\section{Method}

Sample: The sample representing the general population (148 women, 39 men, Mage $=20.7$ years, $\mathrm{SD}=3.2$ ) was recruited at the Université Paris Descartes and consisted of students in the first year of a bachelor's degree in psychology. The participants were informed of the aims of the study and those who agreed to take part gave their signed informed consent. The entire sample consisted of 187 students, 53\% of whom agreed to complete a SCID-II interview. However, only 30 students actually completed the interview, 35 students did not respond to the second part of the study, 34 students refused to participate the interview after reconsideration, and one student was excluded due to the suspicion of a psychotic disorder. The final sample therefore consisted of 186 students who completed SA-SAPAS, with 29 of them also being interviewed using the SCID-II.

\section{Measures}

We used the same tests as in study 1.

Procedure: The study consisted of two parts. In the first part, the students completed the SA-SAPAS and were asked if they wanted to participate in the second stage of the study. If they agreed to do so, they gave their email address and telephone number. They were then informed that they would be contacted within 3 weeks to perform the second part of the study. In the second part, the participants were interviewed using the SCID-II before completing another SA-SAPAS (retest).

Results: The analyses were similar to those performed in the previous study (see study one) except that we also tested for the prevalence of people with PDs. A Wilcoxon-Mann-Whitney test was conducted to analyze the distributional differences compared to the prevalence obtained with the SA-SAPAS for the complete sample of students. The prevalence of individuals with PDs in the sample of students interviewed using the SCID-II $(n=29)$ was $27.6 \%$. The disorders were broken down as follows: $45.4 \%$ borderline, $18.2 \%$ obsessive, $9.1 \%$ histrionic, $9.1 \%$ narcissistic, $9.1 \%$ avoidant, $9.1 \%$ not specified. The mean number of PDs was 1.37 for each patient. Specifically $20.7 \%$ of the students had one PD, 3.4\% had two PDs and $3.4 \%$ had three PDs.

The entire sample $(n=186)$ was considered in the following tests. As in study 1 of the study, internal consistency was analyzed with Spearman's inter-correlations. The results were similar to what we obtained in study 1 , with nearly all the correlations being under 0.2 and not significant. Questions 4 (anger/losing temper) and 5 (impulsivity) were correlated $(r(184)=0.46, p \leq 0.0001)$ and questions 4 (anger/losing temper) and 7 (dependency) were slightly correlated $(r(184)=0.19$, $p \leq 0.01)$. A final significant correlation was found between questions 6 (worrier) and 7 (dependency) $(r(184)=0.24, p \leq 0.001)$. The results relating to the correlations between the items and their confirmatory questions (Table 5) were similar to those found in study 1 . The mean correlations were close to 0.6 .
The Cronbach's a results for the total score indicated that the test achieved moderate consistency $(\alpha=0.45)$. Table 6 shows the different Cronbach's a values. The different items seem to have moderate consistency as was the case for the results from the clinical sample. Questions 4 and 7 had a slightly greater impact on consistency than any of the other items. Overall, the results showed a moderate level of consistency.

Kappa coefficients were used to test the stability of the test. In this sample of 29 participants, question 1 showed aberrant stability $(-0.05)$ while the stability of the other questions was acceptable over time (about 0.70-0.75) (Table 7). This finding probably constitutes an artifact due to the small sample size. The results obtained using Lin's concordance were good regardless of the scoring method used, that is to say with or without confirmatory questions ( 0.90 and 0.94 respectively).

Using the sample of participants that completed the SCID-II interview, we performed an AUC analysis (Table 8). The obtained AUC was 0.88 (95\% CI 0.71-0.97). The cut-off that provided the best balance was 2 or more, which resulted in a correct identification of $86 \%$, a sensitivity of $87.5 \%$, and a specificity of $85.71 \%$. The cut-off of 1 or more did not increase sensitivity, but reduced both specificity (42.9\%) and correct classification (55\%). Although the other cut-off $(\geq 3)$ increased specificity and correct classification (up to $100 \%$ and $89 \%$, respectively), it simultaneously reduced sensitivity (from $87.5 \%$ to $62.5 \%$ ).

In order to analyze the estimate of prevalence of individuals with PDs obtained with the SA-SAPAS, we applied the cut-off of 2 or more to the 186 collected questionnaires. We then compared the distribution of PDs among the sample of 29 students as revealed by the SCID-II interviews (prevalence $27.6 \%$ of people with PDs) with that obtained from the 157 collected SA-SAPAS tests (Table 9). We used a WilcoxonMann-Whitney test to determine whether the two distributions differed significantly from each other. We therefore could conclude that there was no significant difference.

\section{Additional analysis}

We performed an additional analysis for the 3 DSM-IV PD Clusters on our full sample (Study 1 and 2; $N=68$ ). In our sample, the distribution of PDs could not reflect the proper association of PDs due

\begin{tabular}{|l|c|c|c|c|c|c|c|c|}
\hline QUESTION & 1 & 2 & 3 & 4 & 5 & 6 & 7 & 8 \\
\hline & 0.80 & 0.39 & 0.66 & 0.52 & 0.65 & 0.52 & 0.62 & 0.60 \\
\hline
\end{tabular}

Table 5: Inter-correlations between items and their confirmatory questions of the SA-SAPAS in study 2.

\begin{tabular}{|c|c|}
\hline QUESTION & GENERAL SAMPLE (N=186) \\
\hline & Alpha coefficient \\
\hline $\begin{array}{c}\text { Total score } \\
\text { (Scored without confirmatory question) }\end{array}$ & 0.27 \\
\hline $\begin{array}{c}\text { Total Score } \\
\text { (Scored with confirmatory question) }\end{array}$ & 0.45 \\
\hline & Alpha coefficient if item removed \\
\hline Question 1 & 0.43 \\
\hline Question 2 & 0.41 \\
\hline Question 3 & 0.47 \\
\hline Question 4 & 0.33 \\
\hline Question 5 & 0.42 \\
\hline Question 6 & 0.33 \\
\hline Question 7 & 0.42 \\
\hline Question 8 & 0.47 \\
\hline
\end{tabular}

Table 6: Internal consistency of the SA-SAPAS with Cronbach alpha coefficient in study 2. 
Citation: Merlhiot G, Mondillon L, Vermeulen N, Basu A, Mermillod M (2014) Adaptation and Validation of the Standardized Assessment of Personality - Abbreviated Scale as a Self-Administered Screening Test (SA-SAPAS). J Psychol Psychother 4: 164. doi: 10.4172/2161-0487.1000164

Page 5 of 9

\begin{tabular}{|c|c|c|c|c|c|c|c|c|}
\hline QUESTION & 1 & 2 & 3 & 4 & 5 & 6 & 7 & 8 \\
\hline & -0.05 & 0.63 & 1 & 1 & 0.66 & 0.93 & 0.65 & 0.5 \\
\hline
\end{tabular}

Table 7: Kappa coefficient of each item using confirmatory question scoring method of the SA-SAPAS in study 2.

\begin{tabular}{c|c|c|c|c|c|c|c|c|c|}
$\begin{array}{c}\text { GENERAL } \\
\text { SAMPLE } \\
n=29\end{array}$ & $\begin{array}{c}\text { Cut- } \\
\text { off } \\
\text { score }\end{array}$ & Sensitivity & Specificity & + LR & -LR & $+P V$ & $-P V$ & $\begin{array}{c}\text { Correctly } \\
\text { classified } \\
(\%)\end{array}$ \\
\hline $\begin{array}{c}\text { Scored with } \\
\text { confirmatory }\end{array}$ & $\geq 1$ & 82 & 87.5 & 42.9 & 1.53 & 0.29 & 36.8 & 90 & 55 \\
\hline questions & $\geq 3$ & 62.5 & 100 & 0 & 0.37 & 100 & 87.5 & 89 \\
\hline
\end{tabular}

$+\mathrm{LR}=$ Positive likelihood ratio; $-\mathrm{LR}=$ Negative likelihood ratio

$+\mathrm{PV}=$ Positive Predictive Value; $-\mathrm{PV}=$ Negative Predictive Value

$\mathrm{AUC}=$ Area under curve; $\mathrm{Cl}=$ Confidence interval

Table 8: AUC analysis of the SA-SAPAS using the SCID-II interview as gold standard in study 2 .

\begin{tabular}{c|c|c|c|} 
Samples used & $\mathrm{N}$ & $\begin{array}{c}\text { Estimated prevalence of people with PDs (\%) } \\
\text { by using the SA-SAPAS with a cut- off } \geq 2\end{array}$ \\
\hline $\begin{array}{c}\text { Interviewed with } \\
\text { SCID-II }\end{array}$ & 29 & $34.5 \%(\mathrm{Cl} 95 \%: 16 \%$ to $53 \%)$ \\
\hline $\begin{array}{c}\text { Not interviewed } \\
\text { Complete sample }\end{array}$ & 157 & $376 \%(\mathrm{Cl} 95 \%: 29.9 \%$ to $45 \%)$ \\
\hline
\end{tabular}

$\mathrm{Cl}=$ Confidence interval

$\mathrm{PD}=$ Personality disorder

SCID-II = Structured Clinical Interview for DSM-IV Personality Disorders

Table 9: Estimation of the prevalence of people with personality disorder using the SA-SAPAS as a screen-test.

to the lack of PDs in the Cluster A (Cluster A: $\mathrm{N}=3$; Cluster B: $\mathrm{N}=25$; Cluster C: $\mathrm{N}=20$ ). Nevertheless, the applied Spearman correlations revealed a good association with the PDs severity (based on the number of PDs for a single individual) $(r(66)=0.66, p<0.001)$ and a correct association for Cluster B $(r(66)=0.58, p<0.001)$ and Cluster $\mathrm{C}(r(66)=0.48, p<0.001)$. The Cluster $\mathrm{A}$ analysis could not reveal any proper association $(r(66)=0.14, p=0.26)$ because of the low number of participants in this cluster.

\section{Discussion}

In the first stage (pre-test) of our adaptation of the SAPAS, we examined the French version of the SAPAS in its original form as an interviewer-administered questionnaire. A cut-off of 3 or more led to a correct identification rate of $85.7 \%$ with a sensitivity of $87.5 \%$ and a specificity of $83.33 \%$. These results are very similar to the initial findings reported by Moran et al. [16] and to those reported in studies 1 and 2 . It is clear that the confirmatory questions made it possible to retain this quality of classification, since the same AUC analysis without confirmatory questions would not have reached this performance level: AUC of 0.77 (95\% CI 0.6-0.95), with the only available cut-off of 4 giving a sensitivity of $90.3 \%$ and a specificity of $50 \%$. These results are reminiscent of those obtained for the SAPAS-SR [55] which achieved a sensitivity of $80 \%$ and a specificity of only $46 \%$ for a cut-off of 4 (AUC of 0.67 ). It seems that the poor properties of the SAPAS-SR thus result from the absence of any confirmatory questions.

The pre-test revealed the limitations of the SAPAS as an interviewer-administered questionnaire. Moran et al. [16] reported that it took only 2 minutes for an interviewer to complete the test. We found that the conduct of the test required at least 5 minutes and required the interviewers, who were also staff members, to be available at the corresponding times. This makes this version more difficult to implement as a routine screening test and even more so as a screening test for epidemiological studies. These findings led us to adapt it for use as a self-administered questionnaire and to test its properties in both clinical and general samples.

The performances of the SA-SAPAS as revealed in studies 1 and 2 were very efficient. Indeed, while the properties were even better than those exhibited by the previous version, the new version also provided all the benefits of a self-administered questionnaire. In both clinical and general populations, the SA-SAPAS reached the expected internal consistency. This screening test is a self-administrated questionnaire that evaluates different personality traits, which can reduce its consistency. This explains why we obtained a Cronbach coefficient close to 0.40 . Despite the small samples representing both the clinical and general population, we still found a very acceptable Lin's concordance (between 0.89 and 0.94), thus suggesting that the SA-SAPAS exhibits a reasonably good level of stability over time. In study 2 , as far as the test-retest analysis is concerned, we found that question 1 was not stable over time. One possible explanation for this result lies in the fact that this item was rarely completed, meaning that there would be no differences that could reduce the Kappa coefficient to zero. Of the 29 participants, only one answered "yes" to this item in the test phase, while two other subjects answered "yes" in the retest phase. It is known that the Kappa value can sometimes indicates unexpected results due to certain base rate problems $[61,62]$.

The principal aim of this study was to propose a self-administered SAPAS (SA-SAPAS) that could be used as a screening test for PDs in both general and clinical populations. Although, ideally, a single cut-off for both populations would be very convenient, this seemed less easy to achieve without dissipating much of the test's screening capability. However, our results suggest that this is indeed possible and our aims for this test are therefore largely achieved. A cut-off of 2 or more seems robust because the prevalence of people with PDs did not modify the sensitivity or the percentage of correct classifications in our samples. In a general population, this cut-off gives a correct identification rate of $86 \%$ of the population (with $87.5 \%$ sensitivity and $85.7 \%$ specificity). In a clinical population, it permits a very high level of sensitivity $(100 \%)$ coupled with moderate specificity $(50 \%)$ and an excellent level of correct classification of $90 \%$. These results are similar to those obtained by Morse and Pilkonis [26] for the self-administered IPDS AUC of 0.77 , correct identification of $89 \%$, sensitivity of $97 \%$, specificity of $46 \%)$. It is important to note, however, that the SA-SAPAS can also be used with a cut-off of 3 or more. While this significantly increases its sensitivity (80.6\%) and specificity (75\%), it reduces the level of correct classification $(80 \%)$. In this case, the SA-SAPAS's properties again become very similar to those found using the original version [16] (correct classification rate of $90 \%$, sensitivity of $94 \%$, and specificity of $85 \%$, respectively). In addition, these results are mainly due to the use of confirmatory questions in the self-administered questionnaire which proved to be essential in order to retain the good screening properties of the SA-SAPAS. Unlike the results of the SAPAS-SR [30,54,55] which indicated poor screening abilities, our SA-SAPAS version did not lose its screening capacity for PDs.

This self-administered SAPAS (SA-SAPAS) translated into French can be used for a variety of applications. In general or psychiatric clinical populations, a cut-off of 2 or 3 can be used for a routine screening test after admission. In both populations, it is important to determine which individuals might have a PD in order to select patients who would benefit most from an interview and to ensure that appropriate care is administered. The only precautions that need to be taken are to avoid using it as a diagnostic criterion and to avoid 
Citation: Merlhiot G, Mondillon L, Vermeulen N, Basu A, Mermillod M (2014) Adaptation and Validation of the Standardized Assessment of Personality - Abbreviated Scale as a Self-Administered Screening Test (SA-SAPAS). J Psychol Psychother 4: 164. doi: 10.4172/2161-0487.1000164

Page 6 of 9

informing staff of the results, in order to prevent any stigmatization of the patient. Indeed, further investigations would need to be undertaken in order to confirm the presence of a PD.

In general populations, the SA-SAPAS is suitable for use in a variety of basic research applications. A cut-off of 2 or more can be used in epidemiological studies in which it is necessary to obtain an overview of the prevalence of people with PDs, as well as in two-stage studies which involve PD interviews. Another application would be as an exclusion/inclusion tool which could be used to screen for PDs in order to either exclude participants by selecting only those with a negative result on the SA-SAPAS, or to specifically select people with PDs by using a cut-off of 3 .

It should be noted that there are some limitations to our study. Some of the selected samples were small and included a majority of women. However, this does not alter the fact that our data yielded good results. Indeed, these were very similar to those obtained by other studies conducted in the field of screening tests for PDs $[16,26]$. In a recent study, Bukh et al. [50] used the SAPAS in its intervieweradministered form. They obtained moderate performances in a sample of 394 participants with depressive disorders (33\% PD prevalence) for each of their 3 cut-offs: $\geq 2$, correct identification of $56.3 \%$, sensitivity of $95 \%$, specificity of $37 \%$; $\geq 3$, correct identification of $73.1 \%$, sensitivity of $80 \%$, specificity of $70 \%$; $\geq 4$, correct identification of $76.6 \%$, sensitivity of $57 \%$, specificity of $86 \%$. These findings are interesting because they are very similar to those found using a smaller sample [16] and those obtained in the present study. The prevalence of people with PDs found by Bukh et al. [50] was indeed similar to the value we obtained in a general population, except that their sample presented a co-morbidity with depressive disorders. This is why the performance of the SAPAS in its interviewer-administered form was not as informative as in other studies. This might also be due, apart from the influence of the co-morbidity with depressive disorders, to the method of administration. The presence of an interviewer could have a significant impact on the responses given by depressed patients. It would be interesting to see how the SA-SAPAS would perform among this type of population. Moreover, this constitutes a limitation because individuals with PDs may lack of objective perception of their own behaviors. It is the concern of any self-administered instrument, but this does not remove its screening ability. It is one of the reasons why we performed a cluster analysis for the DSM-IV PD clusters in order to check if a specific cluster would be less likely to be screened. Finally, in the same way as any screening test for PDs, it would benefit from other sample validations such as, for example, in primary care structures or in general practitioners' office. This would be beneficial for patients and practitioners alike and make it possible to provide more comprehensive care.

Above, we discussed the association of the SAPAS with DSM-IV PDs and the results obtained by Hesse and Moran [52]. In their sample, these authors found that the SAPAS did not have the same capacity of association for PDs within each of the 3 DSM-IV PD Clusters (A-B-C), with the association being weaker for Cluster $\mathrm{B}$. The performed cluster analysis revealed a good association with PDs severity and a moderate association for Cluster B and C. However, because of the lack of Cluster A PDs in our sample, we could not reveal any proper association with this cluster. This therefore indicates the need for a further analysis of the association of the construct of the SAPAS with PDs. Even though such analyses require a very large sample with a proper distribution of the different PDs, they would obviously lead to a better understanding of the reasons accounting for the SAPAS's good screening capacity for
PDs. In conclusion, the present study has various applications. Our findings suggest that the SA-SAPAS represents a useful short screening test for PDs. Interestingly; this test has many different uses. Depending on the cut-off that is applied, it is possible to use it as a reliable way to assess for PDs (i.e., for clinical use or as an exclusion/inclusion criterion in clinical research) or, alternatively, for fundamental research into personality when a less restrictive cut-off is applied. Moreover, our current experiments suggest that it is possible to use this pre-screening test in clinical and general populations. Importantly, to our knowledge, it is the only short screening test for PDs in French that takes only a few minutes to complete.

\section{References}

1. Huang Y, Kotov R, de Girolamo G, Preti A, Angermeyer M, et al. (2009) DSM-IV personality disorders in the WHO World Mental Health Surveys. Br J Psychiatry 195: 46-53.

2. Johnson JG, Cohen $P$, Kasen S, Skodol AE, Oldham JM (2008) Cumulative prevalence of personality disorders between adolescence and adulthood. Acta Psychiatr Scand $118: 410-413$

3. Zimmerman M, Rothschild L, Chelminski I (2005) The prevalence of DSM-IV personality disorders in psychiatric outpatients. Am J Psychiatry 162: 1911-1918.

4. Newton-Howes G, Tyrer P, Anagnostakis K, Cooper S, Bowden-Jones O, et al (2010) The prevalence of personality disorder, its comorbidity with mental state disorders, and its clinical significance in community mental health teams. Soc Psychiatry Psychiatr Epidemiol 45: 453-460.

5. Moran P (2005). Developments in the epidemiological study of personality disorders. Psychiatry, 4(3), 4-7.

6. Tyrer P, Mulder R, Crawford M, Newton-Howes G, Simonsen E, et al. (2010) Personality disorder: a new global perspective. World Psychiatry 9: 56-60.

7. Tyrer $P$ (2008) Personality disorder and public mental health. Clin Med 8: 423-427

8. Newton-Howes G, Tyrer P, Johnson T (2006) Personality disorder and the outcome of depression: meta-analysis of published studies. Br J Psychiatry 188: $13-20$.

9. Bock C, Bukh JD, Vinberg M, Gether U, Kessing LV (2010) The influence of comorbid personality disorder and neuroticism on treatment outcome in first episode depression. Psychopathology 43: 197-204.

10. Fassino S, Pierò A, Tomba E, Abbate-Daga G (2009) Factors associated with dropout from treatment for eating disorders: a comprehensive literature review. BMC Psychiatry 9: 67.

11. Angres D, Bologeorges S, Chou J (2013) A two year longitudinal outcome study of addicted health care professionals: an investigation of the role of personality variables. Subst Abuse 7: 49-60.

12. First M, Gibbon M, Spitzer R (1997). Structured Clinical Interview for DSM-IV Axis II Personality Disorders (SCID-II). Am. Psychiatr. Press. Inc.

13. Pfohl B, Blum M, Zimmerman M (1997) Structured interview for DSM-IV personality diorders (SIDP-IV). American Psychiatric Press.

14. Loranger AW, Janca A, Sartorius N (1997) Assessment and diagnosis of personality disorders: The ICD-10 international personality disorder examination (IPDE). Cambridge University Press, Australia

15. Van Horn E, Manley C, Leddy D, Cicchetti D, Tyrer P (2000) Problems in developing an instrument for the rapid assessment of personality status. Eur Psychiatry 15 Suppl 1: 29-33.

16. Moran P, Leese M, Lee T, Walters P, Thornicroft G, et al. (2003) Standardised Assessment of Personality - Abbreviated Scale (SAPAS): preliminary validation of a brief screen for personality disorder. Br J Psychiatry 183: 228-232.

17. Davison S, Leese M, Taylor PJ (2001) Examination of the screening properties of the personality diagnostic questionnaire $4+(P D Q-4+)$ in a prison population J Pers Disord 15: 180-194

18. Fossati A, Maffei C, Bagnato M, Donati D, Donini M, et al. (1998) Brie communication: criterion validity of the Personality Diagnostic Questionnaire-4+ (PDQ-4+) in a mixed psychiatric sample. J Pers Disord 12: 172-178.

19. Hyler SE, Skodol AE, Oldham JM, Kellman HD, Doidge N (1992) Validity of the Personality Diagnostic Questionnaire-Revised: a replication in an outpatient sample. Compr Psychiatry 33: 73-77. 
Citation: Merlhiot G, Mondillon L, Vermeulen N, Basu A, Mermillod M (2014) Adaptation and Validation of the Standardized Assessment of Personality - Abbreviated Scale as a Self-Administered Screening Test (SA-SAPAS). J Psychol Psychother 4: 164. doi: 10.4172/2161-0487.1000164

Page 7 of 9

20. Steven E, Rieder RO, Williams JBW, Robert L, Hendler J (1988) The Personality Diagnostic Questionnaire: Development and preliminary results. J Pers Disord 2: 229-237.

21. Ekselius L, Tillfors M, Furmark T, Fredrikson M (2001) Personality disorders in the general population: DSM-IV and ICD-10 defined prevalence as related to sociodemographic profile. Pers Individ Dif 30: 311-320.

22. Ottosson H, Bodlund O, Ekselius L, Grann M, von Knorring L, et al. (1998) DSM-IV and ICD-10 personality disorders: a comparison of a self-report questionnaire (DIP-Q) with a structured interview. Eur Psychiatry 13: 246-253.

23. Morey LC (1997) Personality Assessment Screener (PAS) technical manual Odessa. FI Psychol Assess Resour.

24. Porcerelli JH, Kurtz JE, Cogan R, Markova T, Mickens L (2012) Personality assessment screener in a primary care sample of low-income urban women. J Pers Assess 94: 262-266.

25. Lange J, Geiser C, Wiedl KH, Schöttke, H (2012). Screening for personality disorders: A new questionnaire and its validation using latent class analysis Psychological Test and Assessment Modeling, 54(4): 323-342.

26. Morse JQ, Pilkonis PA (2007) Screening for personality disorders. J Pers Disord 21: 179-198.

27. Trull TJ, Amdur M (2001) Diagnostic efficiency of the lowa personality disorder screen items in a nonclinical sample. J Pers Disord 15: 351-357.

28. Langbehn DR, Pfohl BM, Reynolds S, Clark LA, Battaglia M, et al. (1999) The lowa Personality Disorder Screen: development and preliminary validation of a brief screening interview. J Pers Disord 13: 75-89.

29. Schöttke H, Lange J, Imholz M, Wiedl KH (2011) Entwicklung eines Screening-Verfahrens zur Diagnostik von Persönlichkeitsstörungen: Das Persönlichkeitsstörungs-Screening-Kurzform (PSS-K). Verhaltenstherapie 21: 154-161.

30. Germans S, Van Heck GL, Moran P, Hodiamont PPG (2008) The Self-repor Standardized Assessment of Personality-abbreviated Scale: Preliminary results of a brief screening test for personality disorders. Personal Ment Health 2: $70-76$

31. Germans S, Heck GLV, Hodiamont PP, Elshoff D, Kondakci H, et al. (2013) Validation of two informant-based screening instruments for personality disorders in a psychiatric outpatient population. J Hosp Adm 2: 133-142.

32. McCrae RR, Costa Jr PT, Martin TA (2005) The NEO-PI-3: a more readable revised NEO Personality Inventory. J Pers Assess 84: 261-270.

33. Rottman BM, Kim NS, Ahn WK, Sanislow CA (2011) Can personality disorder experts recognize DSM-IV personality disorders from five-factor model descriptions of patient cases? J Clin Psychiatry 72: 630-639.

34. Samuel DB, Widiger TA (2008) A meta-analytic review of the relationships between the five-factor model and DSM-IV-TR personality disorders: a facet level analysis. Clin Psychol Rev 28: 1326-1342.

35. Widiger TA, Costa Jr PT, McCrae RR (2002) A proposal for Axis II: Diagnosing personality disorders using the five-factor model. In : Personality disorders and the five-factor model of personality, Washington.

36. Costa Jr PT, McCrae RR (1990) Personality disorders and the five-factor model of personality. J Pers Disord 4: 362-371.

37. Tulloch AD, Fearon P, David AS (2008) The determinants and outcomes of long-stay psychiatric admissions: a case-control study. Soc Psychiatry Psychiatr Epidemiol 43: 569-574.

38. Crawford MJ, Price K, Gordon F, Josson M, Taylor B, et al. (2009) Engagement and retention in specialist services for people with personality disorder. Acta Psychiatr Scand 119: 304-311.

39. Crawford MJ, Thana L, Methuen C, Ghosh P, Stanley SV, et al. (2011) Impact of screening for risk of suicide: randomised controlled trial. Br J Psychiatry 198: 379-384

40. Conroy S, Marks MN, Schacht R, Davies HA, Moran P (2010) The impact of maternal depression and personality disorder on early infant care. Soc. Psychiatry Psychiatr Epidemiol 45: 285-292.

41. Conroy S, Marks MN, Schacht R, Davies HA, Moran PA (2010) Maternal personality disorder and babies' exposure to tobacco smoke. Arch Womens Ment Health 13: 439-442.
42. Conroy S, Pariante CM, Marks MN, Davies HA, Farrelly S, et al. (2012) Maternal psychopathology and infant development at 18 months: The impact of maternal personality disorder and depression. J Am Acad Child Adolesc Psychiatry 51: 51-61.

43. Einarsson E, Sigurdsson JF, Gudjonsson GH, Newton AK, Bragason OO (2009) Screening for attention-deficit hyperactivity disorder and co-morbid mental disorders among prison inmates. Nord. J Psychiatry 63: 361-367.

44. Hesse M, Pedersen MK (2008) Protocol: Personality assessment as a support for referral and case-work in treatment for substance use disorders (PASRCstudy). BMC Psychiatry 8: 30

45. Shaw J, Minoudis P, Craissati J (2012) A comparison of the standardised assessment of personality-abbreviated scale and the offender assessment system personality disorder screen in a probation community sample. J Forens Psychiatry Psychol 23: 156-167.

46. Miller S, Crawford MJ (2010) Open access community support groups for people with personality disorder: attendance and impact on use of other services. Psychiatrist 34: 177-181.

47. Schippers GM, Broekman TG, Buchholz A, Koeter MWJ, van den Brink W (2010) Measurements in the Addictions for Triage and Evaluation (MATE) an instrument based on the World Health Organization family of international classifications. Addiction 105: 862-871.

48. Kongerslev M, Moran P, Bo S, Simonsen E (2012) Screening for personality disorder in incarcerated adolescent boys: preliminary validation of an adolescent version of the standardised assessment of personality - abbreviated scale (SAPAS-AV). BMC Psychiatry 12: 94

49. Pluck G, Sirdifield C, Brooker C, Moran P (2012) Screening for personality disorder in probationers: Validation of the Standardised Assessment of Personality-Abbreviated Scale (SAPAS). Personal Ment Health 6: 61-68.

50. Bukh JD, Bock C, Vinberg M, Gether U, Kessing LV, et al. (2010) Clinical utility of Standardised Assessment of Personality - Abbreviated Scale (SAPAS) among patients with first episode depression. J Affect Disord 127: 199-202.

51. Hesse M, Rasmussen J, Pedersen MK (2008) Standardised assessment of personality - a study of validity and reliability in substance abusers. BMC Psychiatry 8: 7.

52. Hesse M, Moran P (2010) Screening for personality disorder with the Standardised Assessment of Personality: Abbreviated Scale (SAPAS): further evidence of concurrent validity. BMC Psychiatry 10: 10.

53. Farrand $P$, Woodford $\mathrm{J}$ (2013) Measurement of individualised quality of life amongst young people with indicated personality disorder during emerging adulthood using the SEIQoL-DW. Qual Life Res 22: 829-838.

54. Jansen BPM, Damen KFM, Hoffman TO, Vellema SL (2012) The Standardized Assessment of Personality - Abbreviated Scale as a screening instrument for personality disorders in substance-dependent criminal offenders. Personal Ment Health 7: 122-132.

55. Söchtig A, Kliem S, Kröger C (2012) Diagnostic efficiency of the German version of the Standardized Assessment of Personality--Abbreviated Scale. Psychopathology 45: 381-389.

56. Donker T, van Straten A, Riper H, Marks I, Andersson G, et al. (2009) Implementation of Internet-based preventive interventions for depression and anxiety: role of support? The design of a randomized controlled trial. Trials 10: 59 .

57. Mann AH, Jenkins R, Cutting JC, Cowen PJ (1981) The development and use of standardized assessment of abnormal personality. Psychol Med 11: 839-847.

58. Bouvard M, Fontaine-Buffe M, Cungi C, Adeleine P, Chapoutier C, et al (1999) Preliminary studies of the structured diagnostic interview for personality disorders: SCID II. Encephale 25: 416-421.

59. Lin L, Hedayat AS, Wu W (2007) A unified approach for assessing agreement for continuous and categorical data. J Biopharm Stat 17: 629-652.

60. Lin LI (1989) A concordance correlation coefficient to evaluate reproducibility. Biometrics 45: 255-268.

61. Hsu LM, Field R (2003) Cohen's Kappa, Scott's p, and Aickin's a. Underst Stat. 2: 205-219.

62. Warrens MJ (2012) Some Paradoxical Results for the Quadratically Weighted Kappa. Psychometrika 77: 315-323. 


\section{$\underline{\text { Appendix }}$}

Self-administered Standardised Assessment of Personality - Abbreviated Scale (SA-SAPAS)

\section{Authors of the original version: Paul Moran et Coll.}

\section{French Version: Gaëtan Merlhiot et Coll.}

Last Name :

First Name :

Age :

Gender :

$\mathrm{M}$

$\mathrm{F}$

Date $: . . . / \ldots / \ldots . .$.

Instructions :

This questionnaire is about how you behave, the way you think and feel things usually, in other words it is about your behavior, your way of being, in general, ("most of the time "and in" most situations ")

Please, read each question carefully, and answer each question by a single response, in fields established for that purpose.

1- In general, do you have difficulty making and keeping friends?

If the answer is yes,

does this apply "most of the time" and in "most situations"?

Tick the appropriate box.

2- Would you normally describe yourself as a loner?

If the answer is yes,

does this apply "most of the time" and in "most situations"?

3- In general, do you trust other people?

If the answer is no,

does this apply "most of the time" and in "most situations"?

4- Do you normally lose your temper easily?

If the answer is yes,

does this apply "most of the time" and in "most situations"?

5- Are you normally an impulsive sort of person?

If the answer is yes,

does this apply "most of the time" and in "most situations"?

6- Are you normally a worrier?

If the answer is yes,

does this apply "most of the time" and in "most situations"?
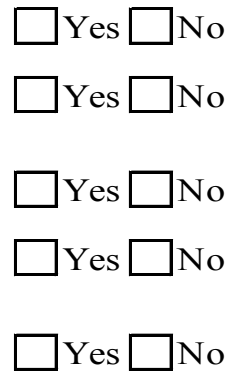

$\square$ Yes $\square$ No

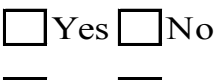

$\square$ Yes $\square$ No

$\square$ Yes $\square$ No

$\square$ Yes $\square$ No

$\square$ Yes $\square$ No

$\square$ Yes $\square$ No

7- In general, do you depend on others a lot?

If the answer is yes,

does this apply "most of the time" and in "most situations"?

$\square$ Yes $\square$ No

$\square$ Yes $\square$ No

8- In general, are you a perfectionist?

$\square$ Yes $\square$ No

If the answer is yes,

does this apply "most of the time" and in "most situations"?

$\square$ Yes $\square$ No 


\section{Self-administered Standardised Assessment of Personality - Abbreviated Scale (SA-SAPAS)}

\section{Auteurs de la version originale: Paul Moran et Coll.}

\section{Version Française : Gaëtan Merlhiot et Coll.}

Nom :

Prénom :

Age :..... Sexe $\square$ H $\square$ F

Date $: . . . / . . . . .$.

\section{Consignes :}

Ce questionnaire s'intéresse à la façon dont vous vous comportez, à votre manière de penser et de ressentir les choses habituellement; c'est-à-dire à propos de votre comportement, de votre manière d'être, en général, (« la plupart du temps » et dans la «plupart des situations »).

Lisez attentivement chacune des questions, et, répondez à chacune d'elles par une seule réponse, au niveau des champs créés à cet effet.

Cocher ce qui convient

1- En général, avez-vous des difficultés à vous faire des amis et à les garder? Si la réponse est oui, est ce que cela s'applique « la plupart du temps » et dans la «plupart des situations »?

$\square$ Oui $\square$ Non Vous décririez-vous comme quelqu'un de solitaire?

Si la réponse est oui,

est ce que cela s'applique « la plupart du temps » et dans la «plupart des situations »?

$\square$ Oui $\square$ Non

3- En général, faites-vous confiance aux autres?

Si la réponse est non,

est ce que cela s'applique « la plupart du temps » et dans la «plupart des situations »? $\square$ Oui $\square$ Non

4- Habituellement, est-ce que vous perdez facilement votre calme?

$\mathrm{Si}$ la réponse est oui,

est ce que cela s'applique « la plupart du temps » et dans la « plupart des situations »? $\square$ Oui $\square$ Non

5- Habituellement, êtes-vous quelqu'un d'impulsif?

$\mathrm{Si}$ la réponse est oui,

est ce que cela s'applique « la plupart du temps » et dans la «plupart des situations »? $\square$ Oui $\square$ Non

6- Habituellement, êtes-vous quelqu'un d'inquiet?

Si la réponse est oui,

est ce que cela s'applique « la plupart du temps » et dans la «plupart des situations »? $\square$ Oui $\square$ Non

7- En général, dépendez-vous beaucoup des autres? $\square$ Oui $\square$ Non

$\mathrm{Si}$ la réponse est oui,

est ce que cela s'applique « la plupart du temps » et dans la «plupart des situations »? $\square$ Oui $\square$ Non

8- En général, êtes-vous un(e) perfectionniste?

$\square$ Oui $\square$ Non

Si la réponse est oui,

est ce que cela s'applique « la plupart du temps » et dans la «plupart des situations »? $\square$ Oui $\square$ Non 